\title{
Arachidonic acid enhances TNF-a-induced tumorigenesis in human breast cancer cell line and rat mammary tumors.
}

\section{Shang-Jung Cheng}

National Taiwan University

Chen-I Ho

National Taiwan University

Ching-Ya Su

National Taiwan University

Hui-Min Su ( $\nabla$ hmsu1203@ntu.edu.tw)

National Taiwan University https://orcid.org/0000-0002-9970-4459

Research article

Keywords: fatty acids, Akt, NF-nB, c-Myc, mammary tumor weight

Posted Date: December 16th, 2019

DOI: https://doi.org/10.21203/rs.2.18909/v1

License: (c) (i) This work is licensed under a Creative Commons Attribution 4.0 International License.

Read Full License 


\section{Abstract}

Background: Our group has previously reported that arachidonic acid (AA, 20:4n-6) levels are 10 times higher in rat mammary tumor tissue compared to the normal mammary gland. Nuclear factor kappaB (NF-KB) activation is often found to be constitutive in human breast cancer, showing higher activation in the more aggressive subtypes. Methods : We incubated the human breast cancer MCF-7 cells for $48 \mathrm{~h}$, in medium supplemented with BSA or BSA-bound 10,50 and $100 \mathrm{mM} \mathrm{AA}$, then added the same medium alone or supplemented with $10 \mathrm{ng} / \mathrm{mL}$ TNF- $a$. Thirty carcinogen-induced rat mammary tumors, weighting between $0.3 \mathrm{~g}$ and $19.2 \mathrm{~g}$, were examined. Results : The carcinogen-induced rat mammary tumor weight was positively correlated with AA level, p-Akt/Akt ratio, nuclear p65, c-Myc and VEGF expression. In MCF-7 cells, AA alone had no effect on NF-kB activation. However, 50 or $100 \mu \mathrm{M}$ AA pretreatment enhanced TNF$\mathrm{a}$-induced $\mathrm{p}$-Akt/Akt, and p-lkB expression, with subsequent decrease in lkB. Thereafter, an increase in nuclear p65, nuclear c-Myc expression, NF-kB gene reporter activity and cell proliferation was observed. Conclusion : AA can effectively augment p-Akt signaling and TNF-a-induced NF-kB activation to promote the tumorigenesis in breast cancer. Our study indicates that AA may influence tumor progression by increasing the aggressiveness of breast cancer.

\section{Background}

We previously found that arachidonic acid (AA, 20:4n-6) levels are 10 times higher in rat mammary tumor tissue than in the normal mammary gland, and are positively correlated with the tumor weight [1]. Most animal, cell culture, and epidemiological studies have shown that n-6 polyunsaturated fatty acids (PUFAs) increase the risk of breast cancer [2-4], however the mechanisms are yet unclear. Therefore, it is of importance to understand the role of AA, the major n-6 PUFA, in breast cancer development. AA is primarily found in phospholipids of membranes and is the precursor of eicosanoids in inflammatory response [5].

Nuclear factor kappaB (NF-kB), a transcriptional factor, is known to regulate inflammatory responses and also play an important role in breast cancer development [6]. In most cells other than B lymphocytes, NF$\mathrm{kB}$ is retained in the cytoplasm as a dimer binding with inhibitory kappaB $(\mathrm{IkB})$ as an inactive form. It is activated by phosphorylation of $\mathrm{lkB}$ ( $\mathrm{p}-\mathrm{lkB}$ ) by Inhibitory kappaB kinase to release the dimeric NF-kB as the active form. Thereafter, IkB is degraded by the $26 \mathrm{~s}$ proteasome-dependent pathway, while the active $\mathrm{NF}-\mathrm{kB}$, mainly p65-p50 complex, is translocated into the nucleus to promote tumorigenesis and angiogenesis [7]. Constitutive NF-kB activation has been detected in human breast cancer and carcinogen-induced rat mammary tumors $[6,8]$. The pro-inflammatory cytokine tumor necrosis factor-a (TNF-a), which is a major mediator between cancer and inflammation, and stimulates NF-kB activation, is also detected in human cancers or rodent tumor tissues [9]. The phosphatidylinositol 3 kinase (PI3K)/Akt (protein kinase B) plays essential roles in proliferation and angiogenesis in human breast cancer [10], and is responsible for TNF-a-induced NF-kB activation [11]. Therefore, we examined the association of AA on Akt signaling, NF-kB activation, and c-Myc expression in carcinogen-induced rat mammary tumors and MCF-7 human breast cancer cells. 
We proposed that AA enhances TNF-a-induced proliferation and investigated this concept in an MCF-7 human breast cancer cell line and rat mammary tumors. We hypothesize that AA may enhance TNF-ainduced $p$-Akt signaling, thereby increasing $\mathrm{p}-\mathrm{lkBa}$ levels. Subsequent decrease in IkBa follows, which in turn, enhances nuclear p65 (RelA) expression, which is a component of the active NF-kB dimer complex. The activated NF-kB mediates NF-kB gene reporter activity and its downstream c-Myc expression to increase proliferation in human breast cancer MCF-7 cells. We also examined the association between the above parameters and weight of the rat carcinogen-induced mammary tumors.

\section{Methods}

\section{Cell culture and reagents}

Culture media were purchased from Gibco Life Technology, and unless otherwise specified, all chemicals were procured from Sigma (St. Louis, MO, USA). MCF-7 cells were obtained from the American Type Culture Collection/Bioresource Collection and Research Center (BCRC) (Taiwan). These cells have performed STR-PCR profile at BCRC. MCF-7 cells were routinely cultured in Dulbecco's modified Eagle medium (DMEM) with L-glutamine and $110 \mathrm{mg} / \mathrm{L}$ of sodium pyruvate, containing $5 \%$ fetal bovine serum (FBS), $100 \mathrm{U} / \mathrm{mL}$ of penicillin and $100 \mu \mathrm{g} / \mathrm{mL}$ of streptomycin at $37^{\circ} \mathrm{C}$ in a $5 \% \mathrm{CO}_{2}$ incubator. For the experiments, the cells $\left(5 \times 10^{4}\right.$ cells $\left./ \mathrm{ml}\right)$ in DMEM containing $5 \%$ FBS were seeded in dishes or plates for $24 \mathrm{~h}$, after which the medium was replaced with DMEM containing $0.1 \% \mathrm{FBS}$, for $24 \mathrm{~h}$. Thereafter, the cells were supplemented with vehicle (bovine serum albumin, BSA) or BSA-bound AA, as described previously [12], and were incubated for $48 \mathrm{~h}$, before stimulation with $10 \mathrm{ng} / \mathrm{mL}$ TNF-a for the indicated time.

\section{Rat mammary tumors}

The rat mammary tumors were the same as those used in our previously published study, where female rats were exposed to a high fat diet, containing $20 \%$ of sunflower oil by weight, with or without n-3 PUFAenriched fish oil supplementation, either during the perinatal period via maternal intake, or during puberty or adulthood [13]. Briefly, the pregnant Sprague-Dawley rats (8 weeks old) at Day 2 of gestation $(n=22)$, were obtained from BioLasco Taiwan, a technology licensee of Charles River Laboratories in Taiwan, and were housed in an individual standard cage in a humidity-controlled room at $24 \pm 1^{\circ} \mathrm{C}$ on a 12 -h light-dark cycle with free access to tap water and the diet. The protocols and animal treatments used in this study were approved by the Animal Care and Use Committee of the National Taiwan University College of Medicine. The pregnant rats were fed a sunflower oil diet with or without n-3 PUFA-enriched fish oil supplementation, prepared in our laboratory, from Day 2 of gestation and continued throughout pregnancy and lactation. After weaning at postnatal Day 22, all the pups were fed chow diet (5001, LabDiet) throughout their lifetime. On Postnatal Day 28 , the female offsprings born to the rats who had been fed with a diet lacking fish oil supplementation, were randomly assigned to give no fish oil 
supplementation, or were supplemented by oral gavage with fish oil (Leiner Health Products, California, USA) per day (for 42 days), on Postnatal Days 30-71, or Postnatal Days 110-151. Mammary tumors were induced by a single intragastric administration of $10 \mathrm{mg}$ of 7,12 dimethylbenzanthracene (DMBA) (Sigma) $(10 \mathrm{mg} / \mathrm{mL}$ in peanut oil) to the female offspring on Postnatal Day 55. The rats were sacrificed at age of postnatal Day 230. Rats were anesthetized with $\mathrm{CO}_{2}$, following which, the mammary tumors were dissected out, weighed, frozen in liquid nitrogen and stored in $-80^{\circ} \mathrm{C}$ freezer. Thirty mammary tumors weighing $0.3 \mathrm{~g}$ to $19.2 \mathrm{~g}$, were collected from 7 or 8 tumor-bearing rats per group (total rats, $\mathrm{n}=$ $30)$, and randomly pooled.

\section{Western blot analysis}

To prepare whole cell or tissue lysates, the cells or pieces of rat mammary tumors were washed with icecold PBS, followed by homogenization and sonication in lysis buffer as described previously $[12,14]$. Nuclear fractions were prepared by extraction with hypotonic and hypertonic buffers as described before [15]. The antibodies used were rabbit monoclonal antibodies against p-Akt or GAPDH (both from Cell Signaling); rabbit polyclonal antibody against p-lkBa IkBa, p65 (all from Santa Cruz), Akt (Cell Signaling), VEGF (Millipore); mouse monoclonal antibodies against Histone H2B (Millipore), c-Myc (ThermoFisher) or b-actin (Sigma).

\section{Fatty acid analysis}

The fatty acid methyl esters were prepared as described previously [16]. Briefly, total lipids were extracted, dried down under nitrogen gas and converted to their methyl esters, which were analyzed by an Agilent $7820 \mathrm{~A}$ gas chromatograph using flame ionization detection on a SP-2560 polar fused silica capillary column (100 m x $0.25 \mathrm{~mm} \times 0.2 \mathrm{um}$, Supelco, Inc) with nitrogen as the carrier gas.

\section{NF-kB dual-Luciferase reporter assay}

The transient transfection and luciferase gene reporter assays were performed as described previously [17]. Briefly, the cells in DMEM containing 5\% FBS, were seeded in 24-well plates for $24 \mathrm{~h}$, after which the medium was replaced with DMEM containing $0.1 \%$ FBS for $24 \mathrm{~h}$. Thereafter, the medium was supplemented with BSA or BSA-bound $50 \mathrm{mM} \mathrm{AA}$ and incubated for $24 \mathrm{~h}$, before transfection. Transient cotransfection was performed with pNF-kB luciferase (firefly) reporter plasmid (Panomics, Fermont, CA, USA) and Renilla phRL-TK luciferase plasmid (Promega, Inc.) as an internal control reporter vector using lipofectamine 3000 reagent (Invitrogen, Inc.) according to the manufacturer's instruction. Twenty-four hours after the transfection, the cells were treated with or without $10 \mathrm{mM} \mathrm{LY} 2940002$ for $1 \mathrm{~h}$, following which, the cells were stimulated with or without $10 \mathrm{ng} / \mathrm{mL}$ TNF-a for $6 \mathrm{~h}$. Firefly and Renilla luciferase 
activities were measured using the Dual-Luciferase reporter assay system kit (Promega, Madison, WI, USA) according to the manufactures' guidelines. Results were normalized by Renilla luciferase luminescence intensity. All samples were tested in triplicate for one experiment and each experiment was repeated 5 times.

\section{${ }^{3} \mathrm{H}$-thymidine incorporation assay}

MCF-7 cells were seeded in 24 well plates for $24 \mathrm{~h}$. Thereafter, the medium was replaced with DMEM containing $0.1 \%$ FBS for $24 \mathrm{~h}$. The cells were then treated with BSA or BSA-bound 10, 50 and $100 \mathrm{mM} \mathrm{AA}$ for $48 \mathrm{~h}$. Following this incubation, the cells were stimulated with or without $10 \mathrm{ng} / \mathrm{mL}$ TNF-a for $6 \mathrm{~h}$. The cells were washed with PBS and incubated with $8 \mathrm{uCi} / \mathrm{mL}$ of ${ }^{3} \mathrm{H}$-thymidine (PerkinElmer, MA, USA) in FBSfree DMEM for $3 \mathrm{~h}$; the reaction was stopped by adding of $10 \%$ cold-trichloroacetic acid and incubating further for $45 \mathrm{~min}$. The ${ }^{3} \mathrm{H}$-thymidine containing medium was removed and the cells were washed three times with cold PBS, following which, $0.4 \mathrm{~N} \mathrm{NaOH}$ was added and incubated for $1 \mathrm{~h}$. The contents of the wells were transferred to tubes containing Scintillation solution (Scintran cocktail T, BDH Chemical, Poole, UK) and counted in a beta-counter (HIDEX 300SL). All samples were tested in triplicate for one experiment and each experiment was repeated 6 times.

\section{Statistical analysis}

The data are presented as mean \pm SEM. The two-way analysis of variance (ANOVA), followed by Bonferroni post hoc analysis was used to compare group effects. Correlation analysis was performed by Pearson correlation coefficient. GraphPad Prism 7.0 (Graph Pad Software, Inc., San Diego, CA, USA) was used to perform graphical and statistical analysis. A p value $£ 0.5$ was considered statistically significant.

\section{Results}

The association between rat mammary tumor weight and AA levels, p-Akt/Akt ratio, IkB, nuclear p65, cMyc or VEGF expression

Our lab has previous found that AA levels are 10 times higher in rat mammary tumor tissue than in the normal mammary gland, and are positively correlated with the tumor weight [1]. Akt signaling and NF-kB activation play important roles in cancer proliferation and angiogenesis [7]. Constitutive NF-kB activation has been detected in DMBA-induced rat mammary tumors $[6,8]$. Therefore, we examined AA levels, $p$ Akt/Akt ratio, lkB, nuclear p65, c-Myc and VEGF expression in the DMBA-induced rat mammary tumors, weighting between $0.3 \mathrm{~g}$ and $19.2 \mathrm{~g}$ (Fig. 1). We observed that the weight of the rat mammary tumors was significantly positively associated with AA levels (Pearson correlation coefficient $r=0.5671, p=$ $0.002, n=27)($ Fig. $1 A)$, p-Akt/Akt ratio $(r=0.5881, p=0.0006, n=30)($ Fig. 1B), nuclear $p 65(r=0.6289, p$ 
$=0.0002, n=30)(F i g .1 D), c-M y c(r=0.7107, p<0.0001, n=30)$ (Fig. 1E), and VEGF $(r=0.8272, p<$ $0.0001, n=30)(F i g .1 F)$. Further, tumor weights were significantly negatively corrected with IkBa expression ( $r=-0.6894, p<0.0001, n=28)$ (Fig. 1C). Owing to the limitation of tumor weight being less than $0.5 \mathrm{~g}$, tumor tissue was insufficient for fatty acid analysis and therefore, the sample size for AA level analysis was smaller than that taken for the analyses of the other parameters. The similar results were obtained for the association between AA levels in the rat mammary tumor and above parameters, AA levels in the rat mammary tumor showed a significantly positive correlation with $p$-Akt/Akt ratio $(r=$ 0.5521, $p=0.0028, n=27)$, nuclear p65 $(r=0.4853, p=0.012, n=27)$, c-Myc $(r=0.5053, p=0.0085, n=$ $27)$ and VEGF $(r=0.6372, p=0.0004, n=27)$. Further, a significantly negative correlation with $1 \mathrm{kBa}(r=$ $-0.6324, p=0.0005, n=27$ ) expression was observed. These results indicated that AA plays an important role in mammary tumor development, and that, AA levels in rat mammary tumor tissue were positively correlated with the tumor weight. Furthermore, the tumor weights were positivity associated with p-Akt signaling, NF-kB activation, c-Myc and VEGF expression, for tumor development. Moreover, we examined the role of AA without or with TNF-a stimulation on proliferation in MCF-7 human breast cancer cells.

\section{AA incorporation into MCF-7}

We first examined whether the supplemented AA was incorporated into MCF-7 cells (Fig. 2 and Additional file 1: Table S1). After 2 days of culturing the cells with 0-100 mM AA, the AA levels were found to increase from $5.3 \%$ of total fatty acids at $0 \mathrm{mM} \mathrm{AA}$ to $17.2 \%, 24.8 \%$ or $28.8 \%$ of total fatty acids with $\mathrm{AA}$ supplementation of 10,50 and $100 \mathrm{mM}$, respectively. Docosatetraenoic acid (22:4n-6) levels were also found to increase from $0.4 \%$ to $10.9 \%$, with increasing AA supplementation. The increase in AA and 22:4n-6 levels was accompanied by a decrease in the total monounsaturated fatty acids from $53 \%$ to $22 \%$. The monounsaturated fatty acids that were found to be reduced were oleic acid (18:1n-9) from $34 \%$ to $14 \%, 18: 1 n-7$ from $7.2 \%$ to $3.2 \%$ and $16: 1 n-7$ from 7.6 to $2.9 \%$ of the total fatty acids, others being changed by less than $1 \%$. In contrast, the saturated fatty acids and $n-3$ fatty acids showed little change, ranging from $38 \%$ to $35 \%$ and from $2.5 \%$ to $0.9 \%$, of the total fatty acids.

\section{AA and TNF- $a$ on p-Akt signaling and NF-kB activation in MCF-7}

About two-thirds of breast cancers in women are hormone-dependent cancers that contain estrogen receptors. NF-kB activation is found to be constitutive in human breast cancers, often showing higher expression in the more aggressive human breast cancer cell lines such as estrogen receptor-negative MDA-MB-461, but less frequently in estrogen receptor-positive MCF-7, where NF-kB activity can be induced by TNF-a stimulation [18-21]. In order to distinguish the role of AA on NF-kB activity, we further examined the effect of pretreatment of AA, without and with TNF-a stimulation on p-Akt/Akt, p-IkB, IkB, nuclear p65, NF-kB luciferase gene reporter activity, nuclear c-Myc expression, and ${ }^{3} \mathrm{H}$-thymidine 
incorporation in MCF-7 cells. We incubated the cells for $48 \mathrm{~h}$ in culture medium supplemented with BSA or 10,50 and $100 \mathrm{mM} \mathrm{AA}$, after which the same medium was added alone or with $10 \mathrm{ng} / \mathrm{mL}$ TNF-a.

Western blotting was performed to study the effect of AA treatment, with or without TNF-a stimulation on the p-Akt/Akt ratio (Fig 3). Two-way ANOVA revealed a main effect of both AA and TNF-a without a AA $x$ TNF-a interaction on p-Akt/Akt ratio. The p-Akt/Akt ratio was significantly increased in response to treatment with 10-100 mM AA for $48 \mathrm{~h}$, and was significantly induced by treatment with TNF-a for 20 min. Moreover, $\mathrm{p}$-Akt/Akt ratios induced by TNF-a were significantly enhanced after pretreatment with 10-100 $\mathrm{mM}$ AA for $48 \mathrm{~h}$, compared to controls $(0 \mathrm{mM})$.

Furthermore, the effect of AA and TNF-a interaction on p-lkBa, lkBa and nuclear p65 expression was revealed by two-way ANOVA in the cells that received treatment with both, AA and TNF-a (Fig. 4). AA treatment alone had no effect on p-lkB (Fig 4B), lkBa (Fig 4C) and nuclear p65 (Fig 4D) expression. Significant effects were observed in TNF-a stimulated cells. Compared to the $0 \mathrm{mM}$ AA with TNF-a stimulation, pretreatment with 50 or $100 \mathrm{mM} \mathrm{AA}$, significantly enhanced TNF-a stimulated increase in $p$ $\mathrm{IkBa}$, with a subsequent decrease in $\mathrm{lkBa}$, and increase in nuclear p65 expression. These data suggest that 50 or $100 \mathrm{mM}$ AA enhances the TNF-a-induced NF-kB activation.

To further evaluate NF-kB reporter luciferase activity after AA and TNF-a stimulation, we transfected MCF7 cells with a NF-kB-driven luciferase reporter plasmid and pretreated it with $50 \mathrm{mM}$ AA before, and TNF-a stimulation after, transfection. The NF-kB reporter luciferase activity was significantly increased by TNF-a stimulation and AA significantly enhanced the TNF-a stimulated luciferase activity (Fig 5). AA alone, without TNF-a stimulation, had no effect on the NF-kB reporter luciferase activity. Further, we used a PI3K/Akt inhibitor, LY294002, to study the effect of LY294002 and AA interaction on the NF-kB reporter luciferase activity. Two-way ANOVA revealed that LY294002, significantly decreased TNF-a stimulated NF-kB luciferase activity and AA significantly inhibited the effect of LY294002 on NF-kB reporter luciferase activity. These results suggest that AA alone has no effect on NF-kB activation, while AA pretreatment enhances TNF-a stimulation, with subsequent increase in p-Akt signaling, decrease in IkB expression and increase in NF-kB activation in MCF-7.

\section{AA and TNF- $\mathrm{a}$ on nuclear c-Myc expression and ${ }^{3} \mathrm{H}$-thymidine incorporation assay in MCF-7}

Western blotting was performed to study the effect of AA treatment with or without TNF-a stimulation, two-way ANOVA revealed a main effect of both AA and TNF-a without a AA x TNF-a interaction on nuclear c-Myc expression (Fig. 6A). Nuclear c-Myc expression was significantly increased by treatment with 10$100 \mathrm{mM}$ AA for $48 \mathrm{~h}$ and was significantly induced by TNF-a treatment for $24 \mathrm{~h}$. It is noteworthy that nuclear c-Myc expression induced by TNF-a was significantly enhanced after pretreatment for $48 \mathrm{~h}$ with 10-100 mM AA, compared to untreated controls ( $0 \mathrm{mM} \mathrm{AA}$ ). The data suggests that AA can effectively increase and enhance TNF-a-induced nuclear c-Myc expression. ${ }^{3} \mathrm{H}$-thymidine incorporation assay (Fig. 
6B), two-way ANOVA revealed main effect of AA but no effect of TNF- $a$ and no AA x TNF-a interaction, indicating that treatment with AA significantly augmented MCF-7 cell proliferation.

These results indicates that AA supplemented in the culture medium was incorporated by the cells, which significantly increased the $\mathrm{p}$-Akt/Akt ratio, nuclear c-Myc expression and ${ }^{3} \mathrm{H}$-thymidine incorporation for cell proliferation, but had no effect on NF-kB activation. However, stimulation with TNF-a significantly increased the NF-kB activation including p-lkB, nuclear p65 expression and NF-kB transcriptional activity, and nuclear $\mathrm{C}-\mathrm{Myc}$ expression. Moreover, these effects were significantly enhanced after pretreatment with 50-100 mM AA. Interestingly, supplementation with $50 \mathrm{mM}$ AA had no effect on NF-kB transcriptional activity, which was significantly increased in response to TNF-a stimulation, but was inhibited by Ly294002. Nevertheless, AA significantly enhanced TNF-a induction and reversed Ly294002 inhibition on NF-kB reporter activity. These results suggest that AA enhances TNF-a-induction, even though, it is unable to influence NF-kB activation, independently.

\section{Discussion}

We have previously reported that AA levels are ten times higher in rat mammary tumor tissue than in the normal mammary gland, and are positively correlated with the tumor weight [1]. Therefore, we examined the effect of AA on breast cancer proliferaton. We found that rat mammary tumor AA levels, p-Akt/Akt ratio, nuclear p65, c-Myc and VEGF expression were positively correlated and IkB expression was negatively correlated with rat tumor weight. Supplementation with 10-100 mM AA increased the AA levels, $\mathrm{p}$-Akt/Akt ratio and nuclear c-Myc expression, as well as cell proliferation in MCF-7 human breast cancer cells. Increases in the p-Akt/Akt ratio and p-lkB, with a subsequent decrease in IkB and increase in nuclear p65 and nuclear c-Myc expression and NF-kB gene reporter activity induced by TNF-a, were enhanced by 50-100 mM AA pretreatment. In addition, AA decreased the inhibitory effect of the PI3K/Akt inhibitor Ly294002, on the TNF-a-induced NF-kB gene reporter activity.

NF-kB DNA-binding activity and nuclear NF-kB expression (including p65, p50 or c-Rel) is often found to be constitutive in human breast cancer tissues, and in carcinogen DMBA-induced rat mammary tumors $[8,18,22]$. Typically, constitutive NF-kB activation is found to be higher in more aggressive breast cancers with highly proliferative properties [23]. The inflammatory human breast cancer with higher tendency to metastasize, shows upregulated gene expression of NF-kB, including p65, p50, p52, p105 or c-Rel, VEGF and other genes involved in proliferation and angiogenesis [24]. It has been reported that AA levels in the human breast cancer tissue are significanltly higher than the normal and/or benign tissues obtained from the margins of the excised tumor of the same breast [25, 26]. Moreover, AA levels are higher in the breast adipose tissues in patients with breast cancer than in controls [27]. Additionally, AA levels in human breast cancer tissues were found to be positively correlated with p-Akt, p-S6, cPLA2 and VEGF expression, albeit, the sampel size was 8 [28]. In the present study, we found that the tumor weight in the DMBAinduced rat mammary tumors was positively correlated with AA levels, p-Akt/Akt ratio, nuclear p65, c-Myc and VEGF expression. In addition, the association between AA levels in the rat mammary tumor and above parameters, similar results were obtained, such that AA levels were positively associated with p- 
Akt/Akt ratio, nuclear p65, c-Myc and VEGF expression in the rat mammary tumors. These results suggest that AA plays an important role in mammary tumor development and AA enhances p-Akt signaling, NF-kB activation, c-Myc and VEGF expression promoting tumor growth and angiogenesis. Our findings indicate that AA may enhance tumor progression by increasing the aggressiveness of mammary tumors.

Many studies demonstrated that NF-kB DNA-binding activity and nuclear NF-kB expression including p65, p50, p52 or c-Rel are constitutive, especially showing higher expression in more aggressive human breast cancer cell lines and human breast cancer tissues $[6,18,19,21]$. In comparison to the more aggressive human breast cancer cell lines such as MDA-MB-231, MDA-MB-438 or SKBR3, MCF-7 shows less NF-kB activity, however, its activity can be induced by TNF-a stimulation [18-21]. We found that AA alone had no effect on NF-kB activation, but pretreatment with 50-100 mM AA enhanced TNF-a-induced p-Akt/Akt, and $\mathrm{p}-\mathrm{lkB}$ expression, with subsequent decrease in IkB, and increase in nuclear p65, nuclear c-Myc expression, NF-kB gene reporter activity and cell proliferation in MCF-7 cells. It has been previously reported that 15 mM AA increased p-Akt/Akt expression, NF-kB-DNA binding activity, cell migration and invasion in MDAMB-231 cells [29]. The AA precursor, $90 \mathrm{mM}$ linoleic acid (18:2n-6) has been found to increase the $p$ Akt/Akt ratio, NF-kB DNA binding activity and fascin to induce migration and invasion in MDA-MB-231 $[30,31]$. It is suggested that AA enhances NF-kB activation in human breast cancer cells. It would be interesting to know whether AA could trigger the aggressive potential of human breast cancers.

In MCF-7 cells, 5-50 mM AA treatment was found to increase mTOR signaling, including p-Akt/Akt and pS6/S6 ratio, HIF-1 a expression, VEGF secretion, cell proliferation and angiogenesis [28]. Furthermore, $15 \mathrm{mM}$ AA has been reported to increase $\mathrm{p}$-Src levels and enhance migration in MDA-MB-231 human breast cancer cells [32]. AA, at a concentration of $5 \mathrm{mg} / \mathrm{ml}$ (about $16 \mathrm{mM}$ ), was found to increase cyclin D1 mRNA and proliferation in T-47D human breast cancer cells [33]. Moreover, $30 \mathrm{mM}$ AA has been reported to increase p38 MAPK, heat-shock protein 27, and RhoA activity to induce cell adhesion in MDAMB-435 human melanoma cells [34]. RhoA and RhoC were found to be increased by $10 \mathrm{mM}$ AA to induce cell migration in CaP human prostate cancer cells [35]. It has further been reported that AA induced $\mathrm{Ca}^{2+}$ entry and migration in BON human pancreatic carcinoid cells [36]. p-Akt and nuclear NF-kB expression and the gene expression of NF-kB as well as cyclooxygenase-2 was found to be increased by $16 \mathrm{mM} \mathrm{AA}$ in PC-3 human prostate cancer cells [37]. We found that 10-100 mM AA increased p-Akt/Akt ratio, nuclear c-Myc, expression, promoting cell proliferation in MCF-7 human breast cancer cells. These results suggest that AA plays an important role in cancer proliferation and metastasis. AA metabolites, such as eicosanoids, play important roles in mediating breast cancer development [5]. It will be interesting to distinguish the role of AA or its metabolites in cancer development.

\section{Conclusion}

This study provides in vivo and in vitro evidence that AA is an effective activator that enhances p-Akt signaling and NF- $\triangle \mathrm{B}$ activation to promote tumorigenesis in breast cancer. Furthermore, the rat mammary tumor weight or AA levels, are positively associated with p-Akt/Akt, NF-₫B activation, c-Myc and VEGF expression in these tumors. 


\section{Abbreviations}

AA: arachidonic acid (20:4n-6); Akt: phosphatidylinositol 3 kinase (PI3K)/ protein kinase B; BSA: bovine serum albumin; DMBA: 7,12 dimethylbenzanthracene; FBS: fetal bovine serum; lkB: inhibitory kappaB; NFkB: nuclear factor kappaB; $p$-IkB: phosphorylation of IkB; PUFAs: polyunsaturated fatty acids; TNF-a: tumor necrosis factor-a; VEGF: vascular endothelial growth factor.

\section{Declarations}

\section{Ethics approval and consent to participate}

All applicable international national and/or institutional guidelines for the care and use of animals were followed. All procedure performed in studies involving animals were in accordance with the ethical standards of the Animal Care and Use Committee of the National Taiwan University College of Medicine. Animal Protocol Number 20090133.

\section{Consent for publication}

Not applicable.

\section{Availability of data and materials}

All data generated or analysed during this study are included in this published article and its supplementary information files.

\section{Competing interests}

The authors declare that they have no competing interests.

\section{Funding}

This work was supported by grants from Ministry of Science and Technology of Taiwan (grant NSC-992320-B-002-025-MY3, MOST-101-2321-B-002-083, MOST-102-2321-B-002-062, MOST-103-2320-B-002022-MY3). The funding bodies had no role in study design, data collection, analysis and interpretation and preparation of the manuscript.

\section{Authors' contributions}

$\mathrm{SC}$ and $\mathrm{CH}$ conceived and designed the study. SC, $\mathrm{CH}$ and $\mathrm{CS}$ conducted the research and analyzed the data. HS analyzed the data, wrote the manuscript and had primary responsibility for final content. All authors read and approved the final manuscript.

\section{Acknowledgements}

Not applicable. 


\section{References}

1. Lo CY, Hsieh PH, Chen HF, Su HM: A maternal high-fat diet during pregnancy in rats results in a greater risk of carcinogen-induced mammary tumors in the female offspring than exposure to a highfat diet in postnatal life. Int J Cancer 2009, 125(4):767-773.

2. Larsson SC, Kumlin M, Ingelman-Sundberg $M$, Wolk A: Dietary long-chain $n-3$ fatty acids for the prevention of cancer: a review of potential mechanisms. Am J Clin Nutr 2004, 79(6):935-945.

3. Zheng JS, Hu XJ, Zhao YM, Yang J, Li D: Intake of fish and marine n-3 polyunsaturated fatty acids and risk of breast cancer: meta-analysis of data from 21 independent prospective cohort studies. Bmj 2013, 346:f3706.

4. Zanoaga O, Jurj A, Raduly L, Cojocneanu-Petric R, Fuentes-Mattei E, Wu O, Braicu C, Gherman CD, Berindan-Neagoe I: Implications of dietary omega-3 and omega- 6 polyunsaturated fatty acids in breast cancer. Exp Ther Med 2018, 15(2):1167-1176.

5. Borin TF, Angara K, Rashid MH, Achyut BR, Arbab AS: Arachidonic Acid Metabolite as a Novel Therapeutic Target in Breast Cancer Metastasis. Int J Mol Sci 2017, 18(12).

6. Cao Y, Karin M: NF-kappaB in mammary gland development and breast cancer. J Mammary Gland Biol Neoplasia 2003, 8(2):215-223.

7. Taniguchi K, Karin M: NF-kappaB, inflammation, immunity and cancer: coming of age. Nat Rev Immunol 2018, 18(5):309-324.

8. Sovak MA, Bellas RE, Kim DW, Zanieski GJ, Rogers AE, Traish AM, Sonenshein GE: Aberrant nuclear factor-kappaB/Rel expression and the pathogenesis of breast cancer. J Clin Invest 1997, 100(12):2952-2960.

9. Balkwill F: Tumour necrosis factor and cancer. Nat Rev Cancer 2009, 9(5):361-371.

10. Dillon RL, White DE, Muller WJ: The phosphatidyl inositol 3-kinase signaling network: implications for human breast cancer. Oncogene 2007, 26(9):1338-1345.

11. Ozes ON, Mayo LD, Gustin JA, Pfeffer SR, Pfeffer LM, Donner DB: NF-kappaB activation by tumour necrosis factor requires the Akt serine-threonine kinase. Nature 1999, 401(6748):82-85.

12. Huang LH, Chung HY, Su HM: Docosahexaenoic acid reduces sterol regulatory element binding protein-1 and fatty acid synthase expression and inhibits cell proliferation by inhibiting pAkt signaling in a human breast cancer MCF-7 cell line. BMC Cancer 2017, 17(1):890.

13. Su HM, Hsieh PH, Chen HF: A maternal high n-6 fat diet with fish oil supplementation during pregnancy and lactation in rats decreases breast cancer risk in the female offspring. $J$ Nutr Biochem 2010, 21(11):1033-1037.

14. Chen HF, Su HM: Exposure to a maternal n-3 fatty acid-deficient diet during brain development provokes excessive hypothalamic-pituitary-adrenal axis responses to stress and behavioral indices of depression and anxiety in male rat offspring later in life. J Nutr Biochem 2013, 24(1):70-80.

15. Lu IF, Hasio AC, Hu MC, Yang FM, Su HM: Docosahexaenoic acid induces proteasome-dependent degradation of estrogen receptor alpha and inhibits the downstream signaling target in MCF-7 breast 
cancer cells. J Nutr Biochem 2010, 21(6):512-517.

16. Chung WL, Chen JJ, Su HM: Fish oil supplementation of control and (n-3) fatty acid-deficient male rats enhances reference and working memory performance and increases brain regional docosahexaenoic acid levels. J Nutr 2008, 138(6):1165-1171.

17. Lu SC, Wu HW, Lin YJ, Chang SF: The essential role of Oct-2 in LPS-induced expression of iNOS in RAW 264.7 macrophages and its regulation by trichostatin A. Am J Physiol Cell Physiol 2009, 296(5):C1133-1139.

18. Nakshatri H, Bhat-Nakshatri P, Martin DA, Goulet RJ, Jr., Sledge GW, Jr.: Constitutive activation of NFkappaB during progression of breast cancer to hormone-independent growth. Mol Cell Biol 1997, 17(7):3629-3639.

19. Cogswell PC, Guttridge DC, Funkhouser WK, Baldwin AS, Jr.: Selective activation of NF-kappa B subunits in human breast cancer: potential roles for NF-kappa B2/p52 and for Bcl-3. Oncogene 2000, 19(9):1123-1131.

20. Gionet N, Jansson D, Mader S, Pratt MA: NF-kappaB and estrogen receptor alpha interactions: Differential function in estrogen receptor-negative and -positive hormone-independent breast cancer cells. J Cell Biochem 2009, 107(3):448-459.

21. Yamaguchi N, Ito T, Azuma S, Ito E, Honma R, Yanagisawa Y, Nishikawa A, Kawamura M, Imai J, Watanabe $S$ et al: Constitutive activation of nuclear factor-kappaB is preferentially involved in the proliferation of basal-like subtype breast cancer cell lines. Cancer Sci 2009, 100(9):1668-1674.

22. Vinothini G, Murugan RS, Nagini S: Evaluation of molecular markers in a rat model of mammary carcinogenesis. Oncol Res 2009, 17(10):483-493.

23. Biswas DK, Shi Q, Baily S, Strickland I, Ghosh S, Pardee AB, Iglehart JD: NF-kappa B activation in human breast cancer specimens and its role in cell proliferation and apoptosis. Proc Natl Acad Sci U $S$ A 2004, 101(27):10137-10142.

24. Lerebours F, Vacher S, Andrieu C, Espie M, Marty M, Lidereau R, Bieche I: NF-kappa B genes have a major role in inflammatory breast cancer. BMC Cancer 2008, 8:41.

25. Chang NW, Wu CT, Chen DR, Yeh CY, Lin C: High levels of arachidonic acid and peroxisome proliferator-activated receptor-alpha in breast cancer tissues are associated with promoting cancer cell proliferation. J Nutr Biochem 2013, 24(1):274-281.

26. Hietanen E, Punnonen K, Punnonen R, Auvinen O: Fatty acid composition of phospholipids and neutral lipids and lipid peroxidation in human breast cancer and lipoma tissue. Carcinogenesis 1986, 7(12):1965-1969.

27. Maillard V, Bougnoux P, Ferrari P, Jourdan ML, Pinault M, Lavillonniere F, Body G, Le Floch O, Chajes V: N-3 and N-6 fatty acids in breast adipose tissue and relative risk of breast cancer in a case-control study in Tours, France. Int J Cancer 2002, 98(1):78-83.

28. Wen ZH, Su YC, Lai PL, Zhang Y, Xu YF, Zhao A, Yao GY, Jia CH, Lin J, Xu S et al: Critical role of arachidonic acid-activated mTOR signaling in breast carcinogenesis and angiogenesis. Oncogene 2013, 32(2):160-170. 
29. Villegas-Comonfort S, Castillo-Sanchez R, Serna-Marquez N, Cortes-Reynosa P, Salazar EP: Arachidonic acid promotes migration and invasion through a PI3K/Akt-dependent pathway in MDAMB-231 breast cancer cells. Prostaglandins Leukot Essent Fatty Acids 2014, 90(5):169-177.

30. Serna-Marquez N, Diaz-Aragon R, Reyes-Uribe E, Cortes-Reynosa P, Salazar EP: Linoleic acid induces migration and invasion through FFAR4- and PI3K-/Akt-dependent pathway in MDA-MB-231 breast cancer cells. Med Oncol 2017, 34(6):111.

31. Gonzalez-Reyes C, Marcial-Medina C, Cervantes-Anaya N, Cortes-Reynosa P, Salazar EP: Migration and invasion induced by linoleic acid are mediated through fascin in MDA-MB-231 breast cancer cells. Mol Cell Biochem 2018, 443(1-2):1-10.

32. Navarro-Tito N, Robledo T, Salazar EP: Arachidonic acid promotes FAK activation and migration in MDA-MB-231 breast cancer cells. Exp Cell Res 2008, 314(18):3340-3355.

33. Razanamahefa L, Prouff S, Bardon S: Stimulatory effect of arachidonic acid on T-47D human breast cancer cell growth is associated with enhancement of cyclin D1 mRNA expression. Nutr Cancer 2000, 38(2):274-280.

34. Garcia MC, Ray DM, Lackford B, Rubino M, Olden K, Roberts JD: Arachidonic acid stimulates cell adhesion through a novel p38 MAPK-RhoA signaling pathway that involves heat shock protein $27 . J$ Biol Chem 2009, 284(31):20936-20945.

35. Brown M, Roulson JA, Hart CA, Tawadros T, Clarke NW: Arachidonic acid induction of Rho-mediated transendothelial migration in prostate cancer. Br J Cancer 2014, 110(8):2099-2108.

36. Goswamee P, Pounardjian T, Giovannucci DR: Arachidonic acid-induced $\mathrm{Ca}(2+)$ entry and migration in a neuroendocrine cancer cell line. Cancer Cell Int 2018, 18:30.

37. Hughes-Fulford M, Li CF, Boonyaratanakornkit J, Sayyah S: Arachidonic acid activates phosphatidylinositol 3-kinase signaling and induces gene expression in prostate cancer. Cancer Res 2006, 66(3):1427-1433.

\section{Figures}


A

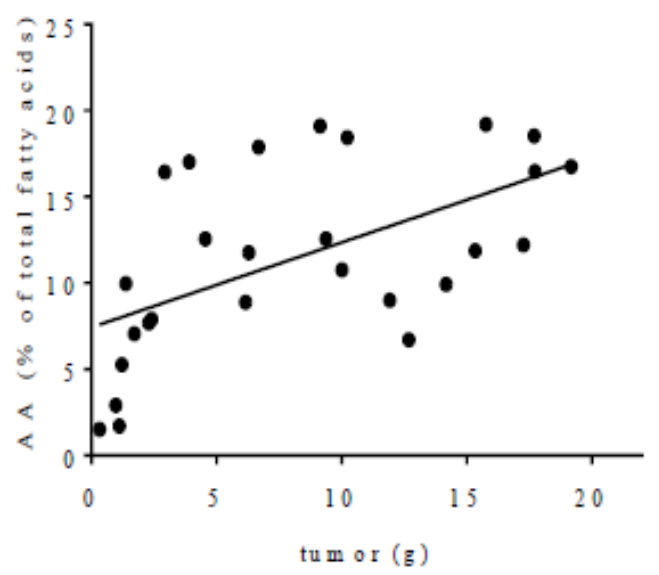

$\mathrm{C}$

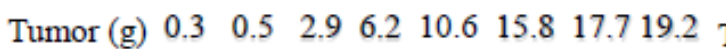

$\mathrm{I \kappa B} \alpha-=--=$

$\beta$-actin $---\cdots-$

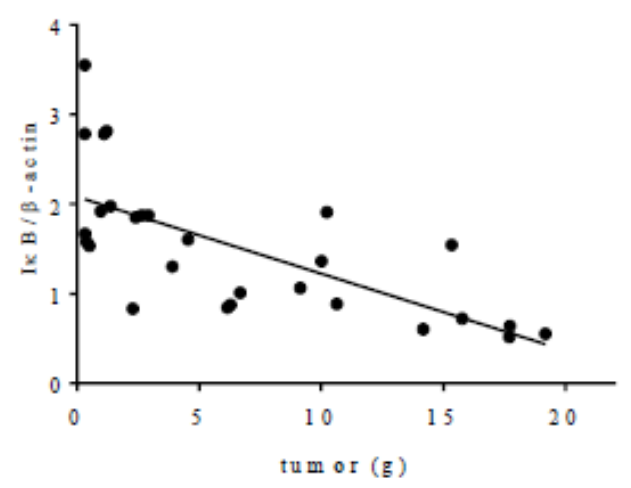

E

$\begin{array}{lllllllll}\text { Tumor }(\mathrm{g}) & 1.0 & 2.3 & 2.9 & 4.5 & 6.2 & 6.7 & 10.6 & 17.7\end{array}$ c-Myc

B-actin

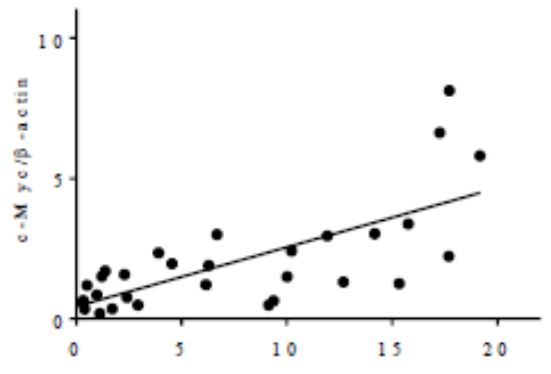

Figure 1

$\mathrm{tw}=\mathrm{or}(\mathrm{g})$
B

$\begin{array}{lllllllll}\text { Tumor (g) } & 0.4 & 1.0 & 2.4 & 4.5 & 10.2 & 14.2 & 17.7 & 19.2\end{array}$

P-Akt

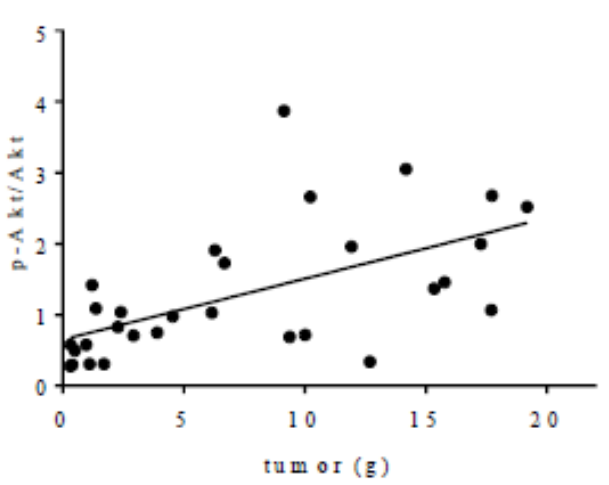

D

umor (g) $1.7 \begin{array}{llllllll}1.7 & 2.4 & 3.9 & 6.2 & 6.3 & 9.1 & 15.3 & 17.7\end{array}$

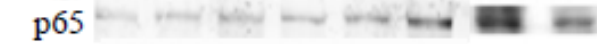
B-actin - - - - - -

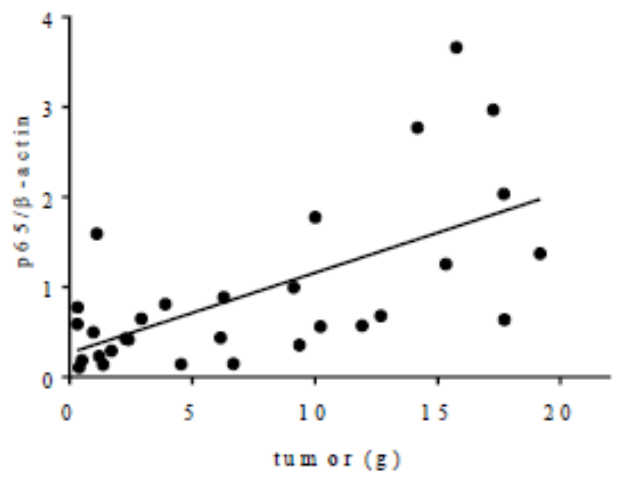

F

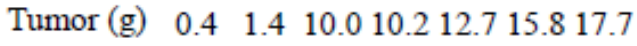
VEGF

GAPDH
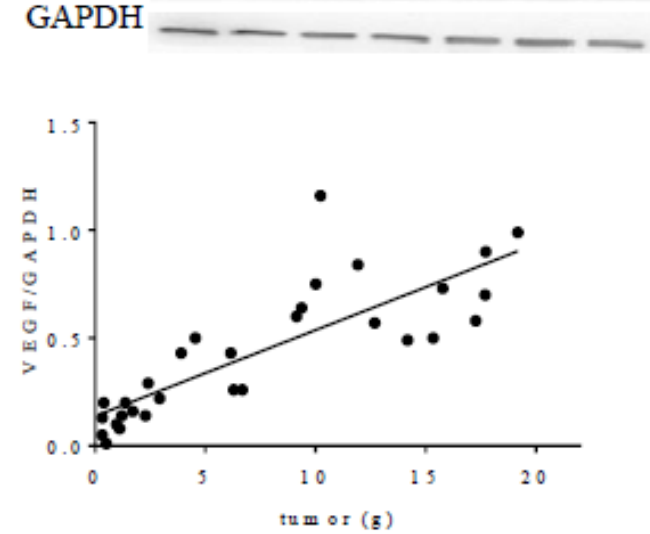

Figure 1

The correlation of DMBA-induced rat mammary tumor weight with tumor AA levels, p-Akt/Akt ratio, IDB nuclear p65, c-Myc or VEGF expression. Mammary tumors, weighing $0.3 \mathrm{~g}$ to $19.2 \mathrm{~g}$, were randomly pooled together for analysis. AA levels are shown as the \% of total fatty acids. Western blot analysis was performed in the tumor homogenate or nuclear fraction lysates, using the indicated antibodies. \-actin or GAPDH was used as loading control. Correlation analysis was performed by Pearson correlation 
coefficient. The weight of rat mammary tumors was significantly associated with (A) AA levels $(r=$ $0.5671, p=0.002, n=27),(B) p-A k t /$ Akt ratio $(r=0.5881, p=0.0006, n=30),(C)$ I $\mathrm{B} \backslash$ expression $(r=$ $-0.6894, p<0.0001, n=28)$, (D) nuclear p65 $(r=0.6289, p=0.0002, n=30),(E) c-M y c(r=0.7107, p<$ $0.0001, n=30)$, and $(F)$ VEGF $(r=0.8272, p<0.0001, n=30)$.

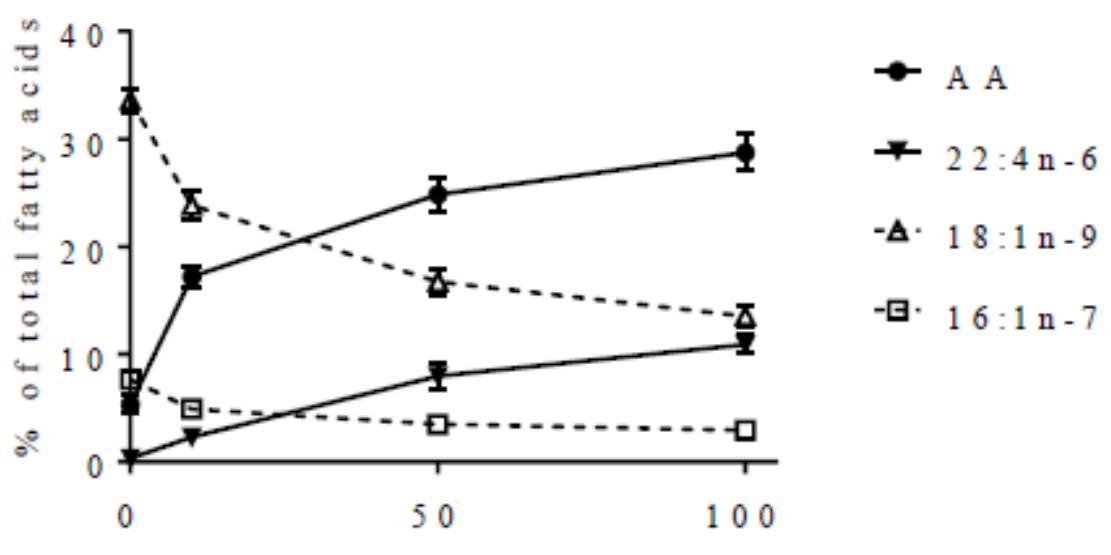

A A $(\mu \mathrm{M})$

Figure 2

Effect of AA supplementation on AA incorporation into MCF-7. Cells were cultured in $0.1 \%$ FBS DMEM supplemented with BSA as vehicle or 10,50, or $100 \mathrm{MM} B S A$-bound AA for $48 \mathrm{~h}$. The levels of AA ( $)$, 22:4n-6 $(\boldsymbol{\nabla}), 18: 1 \mathrm{n}-9(\triangle)$ and 16:1n-7 $(\square)$ are shown as the \% of total fatty acids. The data are presented

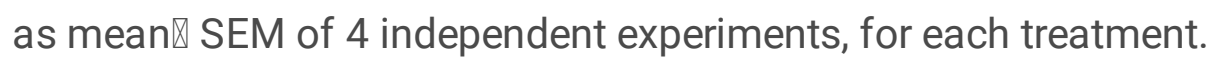




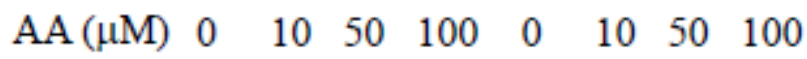

TNF- $\alpha$ - $\quad-\quad-++++$

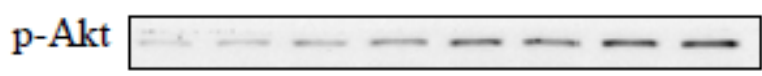

Akt $-\cdots-\cdots-\cdots$

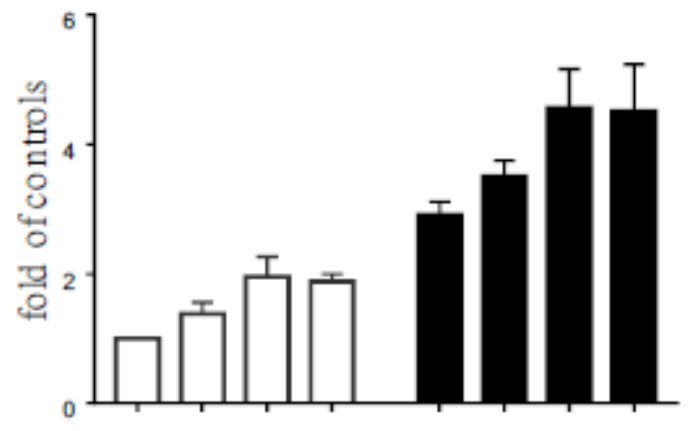

Two-way ANOVA

AA F $(3,24)=5.479, P=0.0052$

TNF- $\alpha \mathrm{F}(1,24)=75.07, P<0.0001$

AA $\times$ TNF $-\alpha \mathrm{F}(3,24)=0.4481 P=0.7209$

\section{Figure 3}

Effect of AA and TNF-a on the p-Akt/Akt ratio in MCF-7. Cells were pretreated with BSA or 10, 50, or 100 口M BSA-bound AA for $48 \mathrm{~h}$, after which, the same medium alone or supplemented with $10 \mathrm{ng} / \mathrm{mL}$ of TNF-

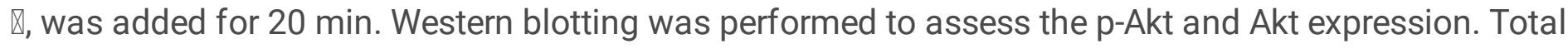
Akt was used as the loading control for $p$-Akt. The levels are expressed as a fold value compared to the BSA-treated control with no TNF- $\triangle$ stimulation. Two-way ANOVA followed by the Bonferroni post hoc test was used to compare AA and TNF- $囚$ effects. The data are presented as mean $\pm S$.E.M for 4 independent experiments for each treatment. 
A

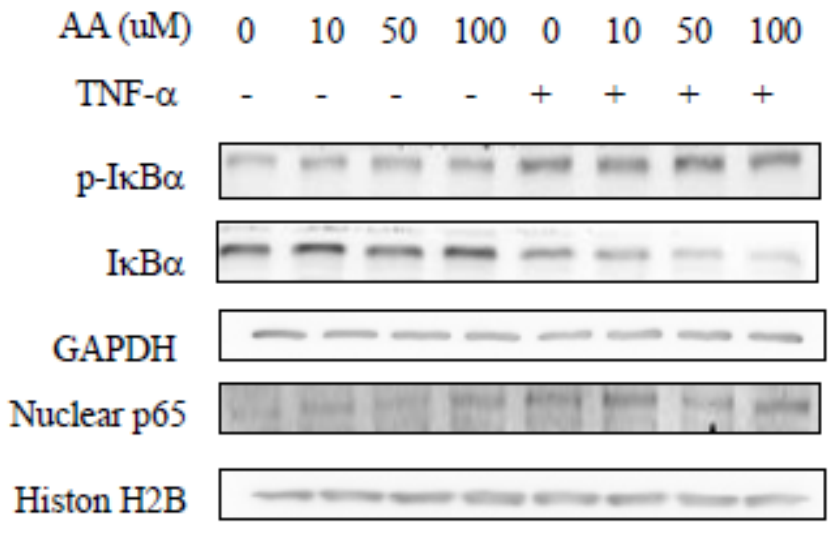

$\mathrm{C}: \operatorname{I\kappa B} \alpha$

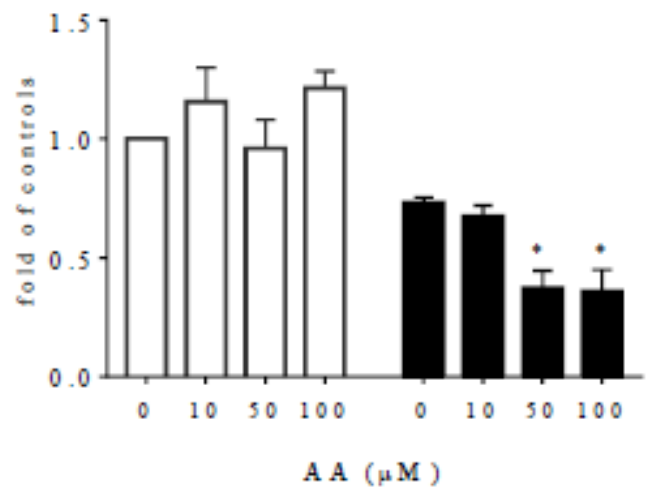

Two-way ANOVA

AA F $(3,24)=3.333, P=0.0363$

TNF $-\alpha \mathrm{F}(1,24)=85.06, P<0.0001$

AA x TNF- $\alpha$ F $(3,24)=4.205 P=0.0159$
B: $\mathrm{p}-\mathrm{I} \kappa \mathrm{B} \alpha$

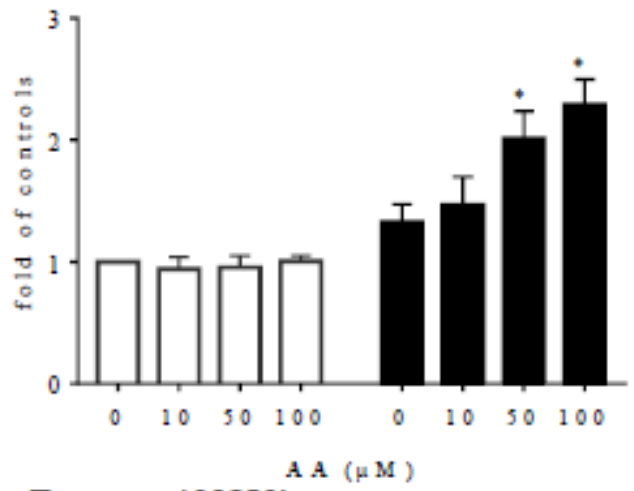

Two-way ANOVA

$\operatorname{AAF}(3,24)=3.951, P=0.0201$

TNF $-\alpha \mathrm{F}(1,24)=24.43, P<0.0001$

AA $x$ TNF- $\alpha \mathrm{F}(3,24)=3.598 P=0.0281$

D: Nuclear p65

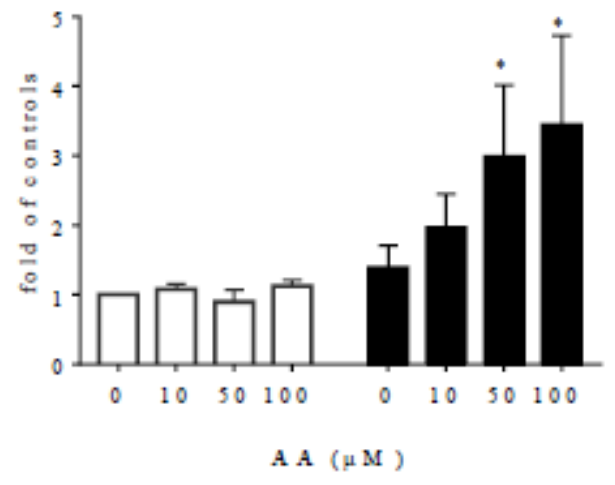

Two-way ANOVA

$\operatorname{AAF}(3,24)=1.263, P=0.3092$

TNF $-\alpha \mathrm{F}(1,24)=11.54, P=0.0024$

AA x TNF- $\alpha \mathrm{F}(3,24)=1.215 P=0.3257$

\section{Figure 4}

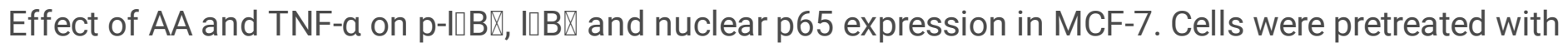
$B S A$ or 10,50 , or $100 \mathrm{aM} B S A$-bound AA for $48 \mathrm{~h}$, after which, the same medium alone or supplemented

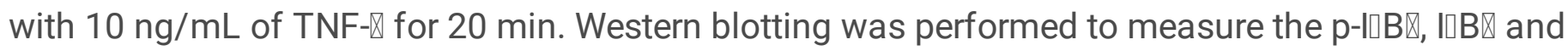
nuclear p65 expression (A). GAPDH was used as the loading control for $\mathrm{p}$-IIB $\mathrm{B}$ (B) and IDBQ (C). Histon $\mathrm{H} 2 \mathrm{~B}$ was used as the loading control for nuclear p65 (D). The levels are expressed as a fold value compared to the BSA-treated control with no TNF- $\triangle$ stimulation. Two-way ANOVA followed by the Bonferroni post hoc test was used to compare AA and TNF- $\square$ effects. * indicates a significant difference

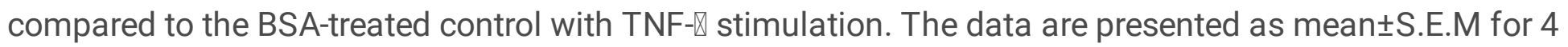
independent experiments. 


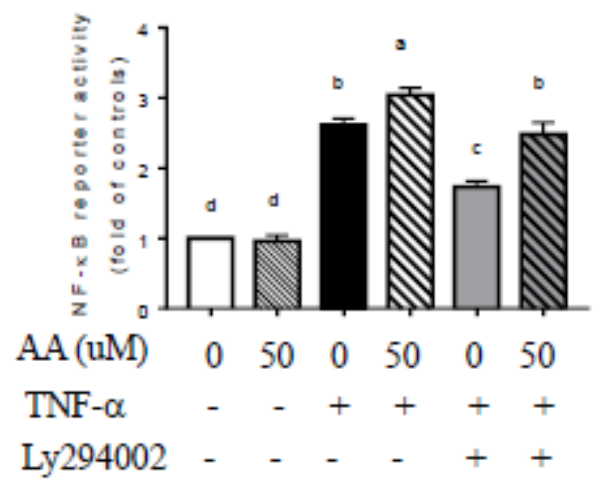

Two-way ANOVA

$\operatorname{AAF}(1,20)=5.634, \mathrm{P}=0.0277$

TNF- $\alpha \mathrm{F}(1,20)=50.2, \mathrm{P}<0.0001$

AA x TNF- $\alpha \mathrm{F}(1,20)=8.175 \mathrm{P}=0.0097$

Two-way ANOVA

$\operatorname{AAF}(1,18)=26.16, \mathrm{P}<0.0001$

Ly $294002 \mathrm{~F}(1,18)=39.1, \mathrm{P}<0.0001$

AAx Ly $294002 \mathrm{~F}(1,18)=1.893 \mathrm{P}=0.1858$

\section{Figure 5}

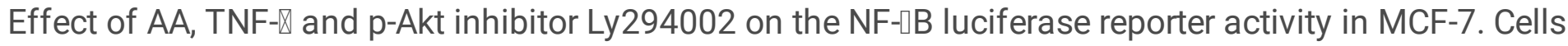
were pretreated with BSA or $50 \mu \mathrm{M}$ AA for $48 \mathrm{~h}$, after which, the same medium containing $10 \mu \mathrm{M}$ LY294002 was added for $1 \mathrm{~h}$, following stimulation with $10 \mathrm{ng} / \mathrm{mL}$ of TNF- $\nabla$ for $6 \mathrm{~h}$. The levels are expressed as a fold value compared to the control BSA-treated cells with no TNF- $\triangle$ stimulation. The different letters indicate significant differences between groups by two-way ANOVA followed by the Bonferroni post hoc test. The data are presented as mean \pm S.E.M for 4-5 independent experiments. 
A

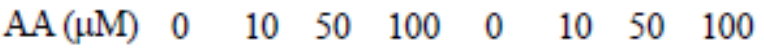
TNF- $\alpha$
$\mathrm{c}-\mathrm{Myc}$

Histon $\mathrm{H} 2 \mathrm{~B}$
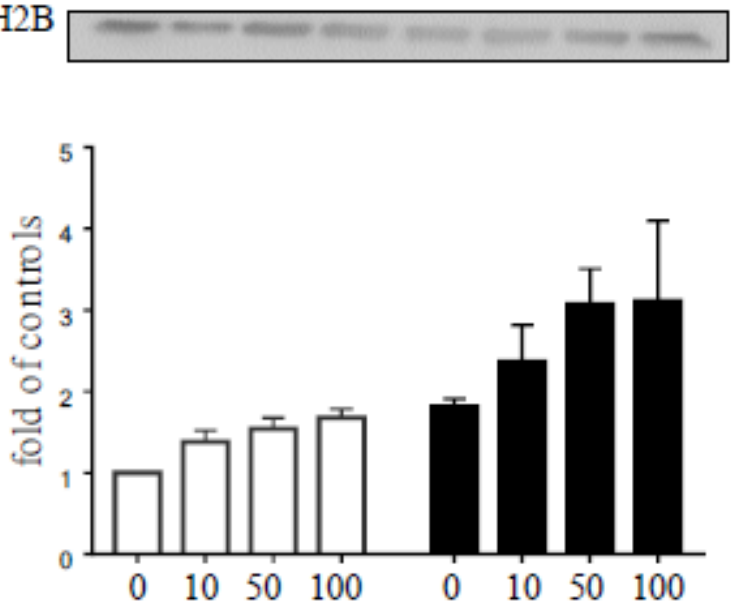

Two-way ANOVA

$\operatorname{AAF}(3,34)=3.435, P=0.0276$

TNF- $\alpha \mathrm{F}(1,34)=23.48, P<0.0001$

AA $\times$ TNF- $\alpha$ F $(3,34)=0.49847 P=0.6858$

B

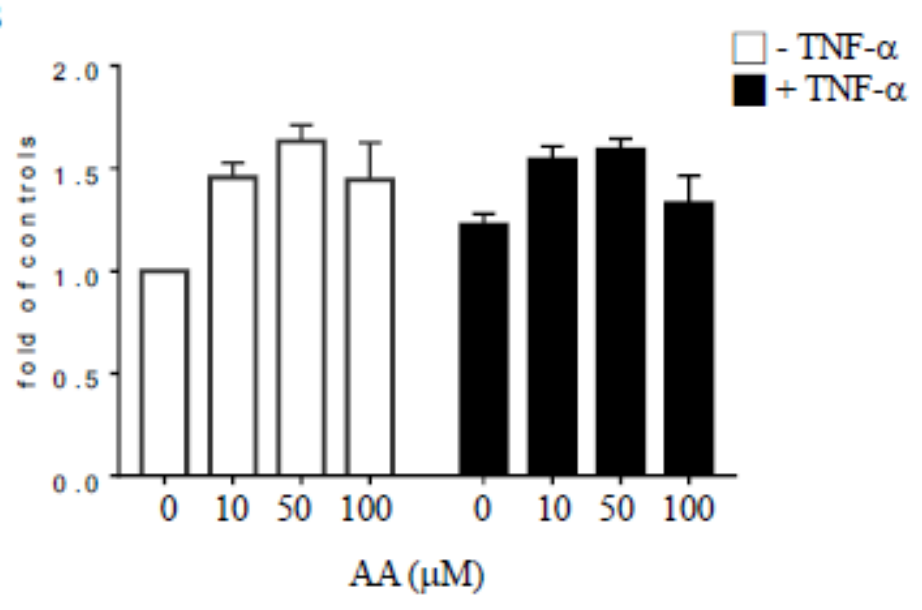

Two-way ANOVA

$\operatorname{AAF}(3,40)=10.21, \mathrm{P}<0.0001$

TNF- $\alpha \mathrm{F}(1,40)=0.3547, \mathrm{P}=0.5548$

AA x TNF- $\alpha \mathrm{F}(3,40)=1.198, \mathrm{P}=0.3227$

Figure 6

Effect of AA and TNF-a on the nuclear c-Myc expression and 3H-thymidine incorporation in MCF-7. Cells were pretreated with BSA or 10,50 , or $100 \mathrm{aM}$ BSA-bound AA for $48 \mathrm{~h}$, after which, the same medium alone or with $10 \mathrm{ng} / \mathrm{mL}$ of TNF- $\rrbracket$ was added for $24 \mathrm{~h}$. Western blots was performed to measure the nuclear C-Myc expression (A). Histone H2B was used as the loading control. Cell proliferation was determined using the $3 \mathrm{H}$-thymidine incorporation assay $(\mathrm{B})$. The levels are expressed as a fold value

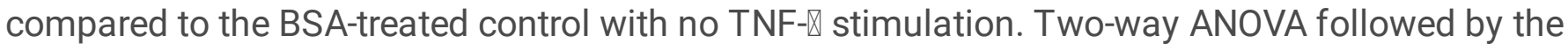


Bonferroni post hoc test was used to compare AA and TNF- $\triangle$ effects. The data are presented as mean $\pm S . E . M$ for 5-6 independent experiments.

\section{Supplementary Files}

This is a list of supplementary files associated with this preprint. Click to download.

- TableS1fattyacidcomposition.pdf

- NC3RsARRIVEGuidelinesChecklistfillable.pdf 